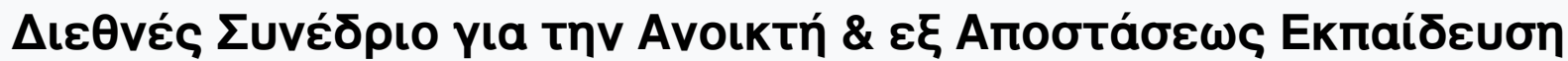

Tóp. 9, Ap. 6B (2017)

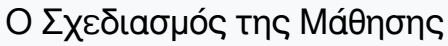

Tónos 6, Mépos B

\section{Практіка́}

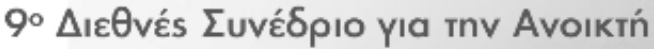

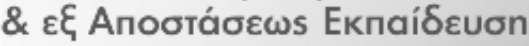

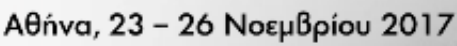

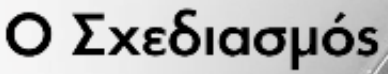
ins MáӨnons

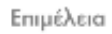

Avióvns Aıvapákns

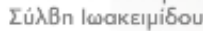

Mapia Niápn

Гке́̉n Mavoúoou

Tóvia Xaproqú

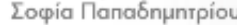

Avva Anoorodibou

ISBN 978.618.5335-01.4

ISBN SET 978-618-82258-5-5

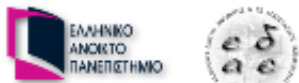

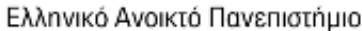

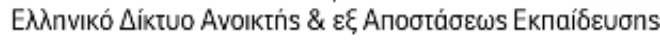

Research findings as tools to support instructional design

Antonia-Maria Hartofylaka, Maria Niari

doi: $10.12681 /$ icodl. 1386 


\title{
Research findings as tools to support instructional design
}

\author{
Antonia-Maria Hartofylaka \\ Sr Instructional Designer \\ DigiMagix \\ thartofylaka@digimagix.gr
}

\author{
Maria Niari \\ PhD Candidate \\ Hellenic Open University \\ niarimaria@gmail.com
}

\begin{abstract}
In the context of the WaW project, the main goal of which is to support women especially elderly and disadvantaged ones- to become entrepreneurs, take action and make their dreams come true, a set of open e-learning courses was written, designed and delivered to the target audience. The e-learning courses cover the subject areas of $21^{\text {st }}$ century skills and crowd-funding and are addressed to women who want to improve their place into workforce or wish to turn an idea of theirs into reality.

Before the design phase of the e-learning courses, a quantitative and qualitative research was conducted simultaneously in four European countries (Norway, Sweden, Spain and Greece), with the aim to understand:

$>$ the target audience level of awareness on the relevant subjects $\left(21^{\text {st }}\right.$ century skills and crowd funding)

the target audience learning preferences.
\end{abstract}

This paper presents the main results of the research, which was conducted in Greece and focuses on the second aim of the research, the learning preferences of the target audience, since these findings are directly linked to the next phase of the project, the design of the e-learning courses, in order to suit the learning needs of the audience.

The research was realised in two phases. First, a pilot quantitative research was conducted through a questionnaire that was distributed to the target audience. The questionnaire was the same for all countries and was designed by the Lifelong Learning Centre of the University of Strathclyde. After two months, a qualitative research was realised through a specialized focus group.

The results between the two phases of the research matched and helped in a significant degree the authors and the instructional designers of the e-learning courses.

Keywords: women support, entrepreneurship, crowd-funding, $21^{\text {st }}$ century skills, elearning, course design, instructional design

\section{Introduction}

For the last seven years, Greece faces an unprecedented socio-economic crisis; one of the main characteristics of this crisis is the extremely high percentage of unemployment, especially in young people and women. According to the Hellenic Statistical Authority, on January 2016 the percentage of unemployment was $\mathbf{2 4 . 4 \%}$, while in the age groups below 24 rises up to $\mathbf{5 1 . 0 \%}$ and in the age groups $\mathbf{2 5 - 3 4}$ to $30.4 \%$.

According to the statistical data, the unemployment in women is even higher $(\mathbf{2 8 . 7 \% ) :}$ 


\begin{tabular}{llrrrrrr}
\hline & & & & & & \\
\cline { 3 - 8 } & & $\mathbf{2 0 1 1}$ & $\mathbf{2 0 1 2}$ & $\mathbf{2 0 1 3}$ & $\mathbf{2 0 1 4}$ & $\mathbf{2 0 1 5}$ & $\mathbf{2 0 1 6}$ \\
\hline Men & 12,4 & 18,6 & 23,9 & 24,3 & 22,5 & 21,1 \\
Women & 18,6 & 25,3 & 30,3 & 30,8 & 29,8 & 28,7 \\
Total & $\mathbf{1 5 , 1}$ & $\mathbf{2 1 , 5}$ & $\mathbf{2 6 , 7}$ & $\mathbf{2 7 , 2}$ & $\mathbf{2 5 , 7}$ & $\mathbf{2 4 , 4}$ \\
\hline
\end{tabular}

Percentage of unemployment per gender, January 2011-2016

As far as the employment status of women is concerned, according to the statistical data, 1 in 3 businesses in Greece do not occupy women in high managerial or other positions in its organisation chart, while the general percentage of women in high managerial positions remain stable in $24 \%$ (Fortune, 2016). Finally, there are 340.000 self-employed women in Greece $(31.62 \%$ of the total number of self-employed persons); the number was slightly increased in the period 2005-2010, perhaps due to the fact that the alternative of a well-paid job had smaller chances.

According to Huang et al. (2006), "public vocational training is one of the major tasks for the modern government to solve the unemployment problem. The e-learning technology has been seen as a potential solution."

But e-learning also addresses to employed people, who turn to continuing education, formal or informal, in order to cope with the continuing changes and the rapid technological and socio-economic development and changes. E-learning seems to be a flexible solution that can be included in their everyday life.

Ten years ago, Karadimas and Papastamatiou (2007) stated that:

"Europe is moving towards a knowledge-based society and economy. More than ever before, access to up-to-date information and knowledge, together with the motivation and skills to use these resources intelligently on behalf of oneself and the community as a whole, are becoming the key to strengthening Europe's competitiveness and improving the employability and adaptability of the workforce. To follow this revolution, it has become evident to all stakeholders that enterprises should improve the knowledge acquisition of their employees, at all the levels of their businesses (from management to production) by providing them lifelong access to learning".

But what do women in Greece think of lifelong learning, when connected to their job acquisition and development?

How do they prefer to learn and what attracts them in a learning program?

From this broader research, in this paper we isolated the answers that were linked to the abovementioned questions and here's what we got.

\section{Quantitative research}

\subsection{Recruitment and sampling procedure}

The target audience of this research was gathered from three different channels:

1. The existing catalogue of contacts, which is consisted mainly of women who had expressed interest in the past to participate in continuing education programs and seminars. The research team contacted directly 50 women of ages mainly between 30-45, the main characteristic of which was the interest in continuing education programs, and informed them of the program scope and the purpose of the questionnaire.

2. Announcements were sent to organisations, such as the General Secretariat for Gender Equality (GSGE) and the Educational Content, Methodology and Technology Laboratory (e-CoMeT Lab) of the Hellenic Open University, 
which responded positively and published the announcement to their webpage and newsletter.

3. Finally, a facebook paid campaign was set. The specific campaign targeted women, ages $28-58$, who live in Greece and have interests, such as: Employment, Career, Curriculum vitae, Application for employment, Women's rights, Crowd-funding etc.

There is no estimation of the number of persons that the questionnaire reached, since it has been published in public websites but a total of 120 questionnaires were returned completed.

\subsection{Participants' profile}

The respondents in Greece were $81.7 \%$ women and $18.3 \%$ men. It is secure to assume that men had been informed through the 2 websites mentioned above, since the other two pools reached women only.

The persons who responded the most were between $30-49$ years old $(85.5 \%)$. The percentage of persons under 29 and over 50 who participated in the questionnaire was low (total $14.5 \%$ ).

- The information regarding the program was communicated through the internet (emails, web pages and social media/facebook), which maybe an excluding factor for a percentage of aged people or people who are not familiar with browsing pages and the social media.

- Age and productivity may affect the overall participation: people who are going through the productive working age (30-50) may show more interest in new ways of working and achieving their goals and dreams while people above certain age maybe reluctant to test new tools and implement new ways of working, co-working, even communicate.

- As far as the age group of 20-29 years-old is concerned, we can assume that they were not informed since:

a. The specific age group was not included in the facebook campaign (it started from 28 years-old).

b. There was no representation of the specific age group in the email lists.

c. The two websites that gave information about the project, both attract visitors from more mature age groups.

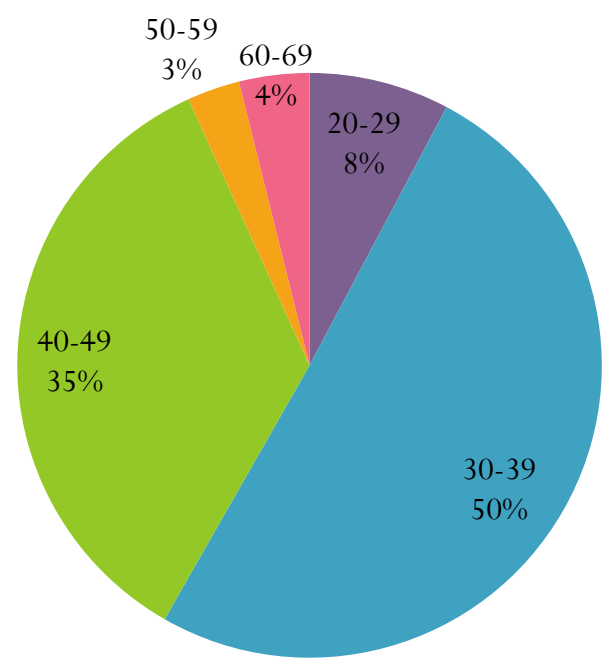

Diagram1. Age profile of the participants 
All of the participants reported as living in Greece. An amazing 82.5\% of the people who responded to the questionnaire is working ( $63.1 \%$ is employed while $19.4 \%$ is self-employed). Unemployed is only the $11.7 \%$ while $3.9 \%$ is retired and $1.9 \%$ is studying. The $35 \%$ of the respondents reported that they worked in the public sector while the $28 \%$ in the private sector. A $13.6 \%$ is working in universities, colleges or schools, an $11 \%$ in business associations and $6 \%$ in NGOs.

Other occupations that were mentioned are: Law offices, Research institutes, Artists, Home-based bakery.

\subsection{Respondents' preferences regarding learning}

According to the respondents' answers, their preferred way of learning about crowdfunding and developing $21^{\text {st }}$ century skills, such as innovating, enterprising, or experimenting skill is by:

1. Learning from other entrepreneurs

2. Case-studies and

3. Solving exercises or practical issues

a. Hands-on, independent exercises designed to stimulate new ways of thinking

b. Working with others to solve a common challenge (collaborative learning)

What follows in their choices is:

- A collection of suggestions, tips, tools and best-practices

- Simulations, models or thought experiments

- Work on unsolved problems

It is important to mention that less than $\mathbf{1 0 \%}$ replied that the review of academic research would help them learn the specific subjects.

Therefore, it was a challenge for the authors and the instructional design team to deliver educational content that would:

$\vartheta$ combine self-paced and collaborative exercises based on real case studies and problems,

$\vartheta$ include the experience (positive or negative) of other entrepreneurs

$\rightarrow$ deliver the theory through examples and real-life situations and scenarios

$\rightarrow$ provide them with tools to create their own course log and portfolio and that would be driven away from a traditional course based on theory.

Let's now move to the findings that derived from the focus group, which was conducted two months after the pilot research. The semi-structured questions that were used were influenced by the abovementioned findings.

\section{Focus Group}

\subsection{Identity of the event}

The focus group discussion was a very interesting procedure, which brought food for thought and enriched the findings of the quantitative analysis.

Thirteen persons participated in the focus group:

- 10 participants (non-experts)

- 1 group discussion leader

- 1 note-taker

\subsection{Participants' profile}

The participants are all Greek women and their ages range from 32 years old to 50 years old. Among them: 
- One works as a teacher in the public sector.

- Three run their own businesses.

- Three work without insurance as teachers providing private lessons (typically they are unemployed).

- Three are unemployed.

The participants received a personal invitation. In total, 20 invitations were sent to people who had already expressed interest in the topic. The team tried to include people from different working environments and various ages. All participants live in the capital of Greece, Athens city.

The event lasted for 2.30 hours; the first 30 minutes were dedicated to ice-breaking activities and two brief presentations about the topics of interest while the rest 2 hours were dedicated to the discussion based on the given questions.

The scope of the presentations were threefold:

a) to make the participants understand the framework, in which they are called to express their viewpoints

b) to clarify the terms, so that we could all speak the same language. According to the Focus group Methodology,

"Before starting, it is important that the project is explained and that key terms are defined. Many survey respondents reported that they did not know what crowd-funding is. It's important that these concepts are first explained so that everyone starts the discussion on a level playing field and is not missing critical information."

c) to give them the opportunity to express their interest in participating to the next steps of the project. At this point, it is important to note that 8 out of 10 participants expressed their interest to take part in the educational program that will emerge from the project while one of them also noted that she might be interested in starting a crowd-funding campaign, after finishing the Curriculum.

In the abovementioned context, the terms "crowd-funding", " $21^{\text {st }}$ century skills", "social enterprise" etc. were explained with many practical examples.

The main phase of the event consists of the discussion, which was based on the predetermined questions devided in 3 thematic groups:

a) Group $1 \rightarrow$ previous experience and future plans: Questions $1 \& 2$

b) Group $2 \rightarrow$ discussion on specific skills: Questions 3,4,5 \& 6

c) Group $3 \rightarrow$ personal viewpoints on the skills that the participants wish to acquire and how they prefer to acquire them: Questions 7,8,9 \& 10

Group 3 is of the interest of this paper and the questions that consist them are the following:

- Question 7: What skills did the participants want to develop?

- Question 8: How would participants like to develop these skills? Would the participants like help?

- Question 9: What is the best way to develop these skills?

- Question 10: What did the participants' think about the idea of learning from other entrepreneurs? Is there another, preferred, method?

After the completion of the discussion, the participants would take a marker with a colour of their choice and right down a word, a phrase or even a doodle from their experience in participating in the focus group. 


\subsection{Sources of information}

The whole process was recorded after the consent of all participants (a consent form was distributed and signed by each one of the participants). In addition, notes were taken by the notes-taker. The following report is based on three sources of information:

1. Recorded file

2. Notes and

3. Papers filled in with key-words from the participants. The participants were placed in a circle, with two desks in the centre that were overlaid with paper. Markers of various colours were available, so that the participants could write down the key-points of their thoughts, opinions as well as emotions.

Each group of questions was linked to a specific colour (for example, first group of questions was linked to blue, second group of questions was linked to green etc). This is an easy trick that eases, later on, the researchers to group and to analyze the information easily.

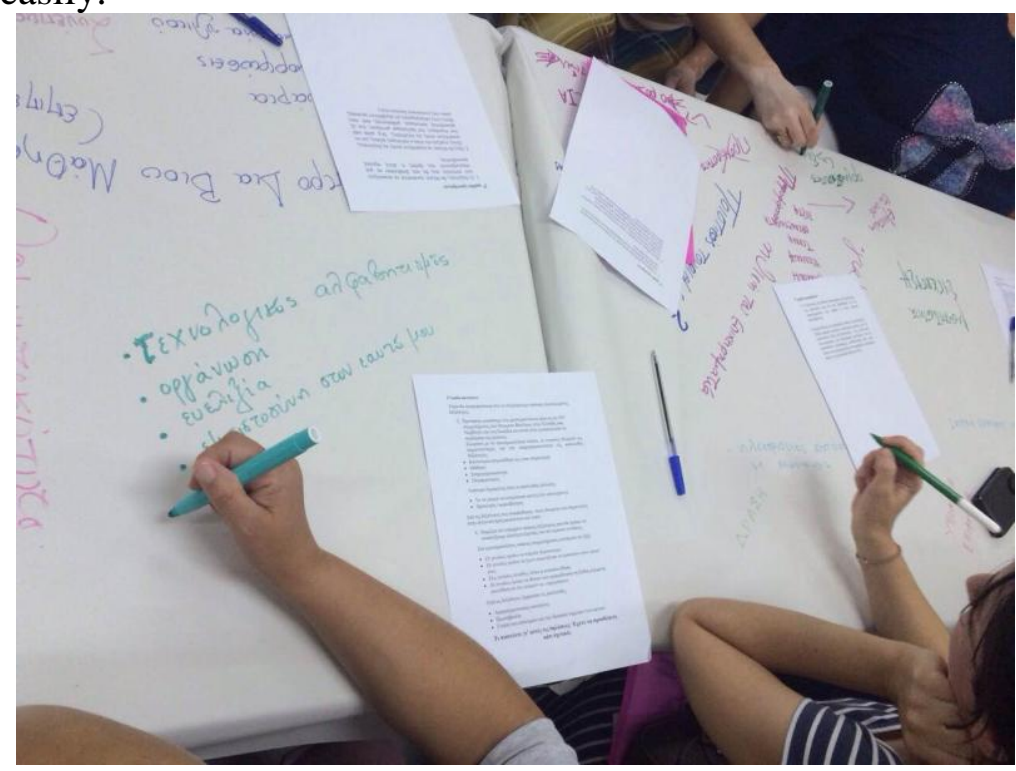

Image 1: The participants as note takers: snapshot of the process

\subsection{Participants' preferences regarding learning}

One of the entrepreneurs said laughing out loud that "if you want to develop these skills and succeed at some point, you have to start your first business and fail. Then start your second business and fail again. At the third attempt, you have much more possibilities to succeed, since you would have gained much experience from the first attempts".

Most of the participants agreed that learning-by-doing and learning from your own experience and mistakes is one of the most productive ways to develop the $21^{\mathrm{st}}$ century skills.

Nearly everybody agreed that seminars with a practical approach that adopt alternative forms of teaching and learning would help them develop their skill. A participant mentioned role-playing as an alternative form of learning and believed that this and similar approaches could engage learners easier than the traditional ones (for example, lectures).

They were all very positive in distance learning and online learning, since these are flexible forms of education and the participants think that they can combine them more easily to their everyday life. Nevertheless, they pinpointed the fact that they 
would not like to study a course that would be based on theory and lack in practice. Practical examples, advices that they could take advantage of, description and analysis of real life events and viewpoints from practitioners are some of the key elements that they would like to have in an e-course's index.

Learning-by-doing, learning from one's own experience and mistakes and seminars would help the target audience to develop the skills they need to.

Regarding seminars, the participants were assertive that they would not select to follow a traditional seminar (for example lectures); instead, they are open to the following approaches:

$\checkmark$ practical approach to learning

$\checkmark$ alternative forms of learning

$\checkmark$ distance learning and online learning

$\checkmark$ learning though examples

$\checkmark$ learning through everyday situations

$\checkmark$ learning by the experts in the field

Finally, the participants highlighted the lack of collaboration in every step of the Greek educational system. Greek people never learned and are not used to cooperate and this is something that has to change. All of them thought that an educational program that promotes collaboration between learners and supports collaborative projects is more appealing and attractive to them.

\section{The challenge}

At the closure of the event, the participants were asked to select a marker with the colour of their choice and right down in a word, a phrase or a doodle, the emotions that derived from their experiences. This is what they wrote:

- Action

- Solidarity

- Cooperation

- Appetite for work

- Hope

- Persistence

- Growth

- Progress

- Knowledge

- Vision

The challenge for the team of writers and the instructional designers' team was respect the participants' feelings and turn the research findings into action, by delivering a high quality content that would attract their interest from the beginning of their study and maintain it vivid until the end of it. In order to achieve that:

$\checkmark$ Each theoretical aspect in both courses is explained with examples, casestudies and interviews from the experts.

$\checkmark$ The examples derive primarily from the host country of the educational program as well as from other European countries.

$\checkmark$ Experiences, positive or negative, of other entrepreneurs were added to the content

$\checkmark$ The students are asked to keep a Course Log, in order to keep track with their thoughts and ideas that would arise while studying.

$\checkmark$ Similarly, they are asked to keep their portfolio active.

$\checkmark$ Tips, tools and best practices were added when possible, as suggested 
$\checkmark$ A combination of self-paced and collaborative exercises based on real case studies and problems was designed

\section{Conclusion}

Both the writing of the educational content and the instructional design process should not be performed in isolation. In many cases, due to the various limits (of time, money and staff), e-learning courses are delivered without previous research. In that way, the needs of the target audience could only be assumed from previous experience or literature review.

In the WaW Erasmus Project, the team had the means to conduct research on the target-audience thoughts and beliefs on their learning needs and the findings from both phases of the research provided valuable information that was put into action in the writing as well as the designing phase of the courses that formed the final Curriculum.

\section{References}

DePutter, M. (2016). Focus Group Methodology. University of Strathclyde. Available at: https://uwawme.eu/resources/. Retrieval date: 15/05/2017.

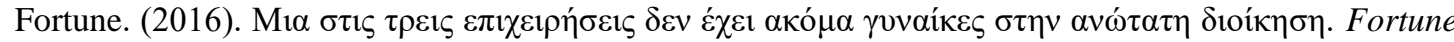
Greece. Available in Greek at: http://www.fortunegreece.com/article/mia-stis-tris-epichirisisden-echi-akoma-ginekes-stin-anotati-diikisi/.

FUNTESO. (2016). Aggregated Report Crowdfunding framework. Available at: https://uwawme.eu/project/intellectual-output-1-aggregated-report-crowdfunding-framework/ Retrieval date: 11/06/2017.

Hellenic Statistical Authority. (2016). Greece in Figures. Available at: http://www.statistics.gr/documents/20181/1515741/GreeceInFigures_2016Q1_EN.pdf/53b7a6 87-807e-4dd5-b8ff-b5ce6c9dc992. Retrieval date: 12/05/2017.

Huang, S., Wei, C., Yu, P., Kuo, P. (2006). An empirical investigation on learners' acceptance of elearning for public unemployment vocational training. International Journal of Innovation and Learning. 2006 Vol.3, No.2, pp.174 - 185. DOI: 10.1504/IJIL.2006.008419.

Skirbekk, V. (2003). Age and Individual Productivity: A Literature Survey. Institute for Demographic Research. Available at: http://www.demogr.mpg.de/papers/working/wp-2003-028.pdf Retrieval date: 02/06/2017.

Uwawme Official Website. (2017). https://uwawme.eu/. Retrieval date: 23/09/2017. 